\title{
Knowledge, Attitude and Intending Practice on Breastfeeding Among Clinical Medical Students in Bingham University Teaching Hospital, Jos
}

\author{
Maryam Shehu ${ }^{1,}$,, Hassan Shehu ${ }^{2}$ \\ ${ }^{1}$ Department of Paediatrics, Bingham University, Karu, Nigeria \\ ${ }^{2}$ Department of Surgery, Bingham University, Karu, Nigeria \\ Email address: \\ maryamshehu1405@gmail.com (M. Shehu) \\ *Corresponding author
}

To cite this article:

Maryam Shehu, Hassan Shehu. Knowledge, Attitude and Intending Practice on Breastfeeding Among Clinical Medical Students in Bingham University Teaching Hospital, Jos. European Journal of Preventive Medicine. Vol. 7, No. 2, 2019, pp. 50-56.

doi: $10.11648 /$ j.ejpm.20190702.13

Received: May 11, 2019; Accepted: June 6, 2019; Published: June 20, 2019

\begin{abstract}
Background: Breastfeeding is a basic human activity, vital to infant and maternal health. A good breastfeeding advice from health professionals can influence a mother's decision to initiate and maintain breastfeeding positively. This study is aimed at assessing clinical medical students' knowledge, attitudes and intending practice towards breastfeeding. Method: Consecutive sampling method was used. Results: Knowledge on the definition of the term EBF was correct in 120 (69.4\%) of the students, $47(27.2 \%)$ of them got it wrong while 6 (3.45) did not known the definition of EBF. The early advantages of EBF was known by over $70 \%$ of the students and the contraindications to BF was gotten by over $60 \%$ of the students. The students' knowledge about some false notion on not giving EBM to sick babies, cause of nipple crack and inadequacy of BF for twin deliveries were good with over $70 \%$ of them knowing the right thing concerning these. The attitude of the students towards BF was very good with over $80 \%$ of them having good attitude towards BF, however $16(9.3 \%)$ will not BF for two years because they believe that it will make their breast to sag, while 23 (13.3) did not know if that is true and $62(77.5 \%)$ disagree with the statement. The intending practice of BF was generally good among the students with over $90 \%$ agreeing to do initiate BF within 6 hours of delivery and practicing EBF for 6 months. The intending practice of BF was generally good among the students with over $90 \%$ agreeing to initiate BF within 6 hours of delivery and practicing EBF for 6 months. The major factors influencing decisions for EBF includes WHO recommendations 108 (48.6\%) out of 222 multiple responses, closely followed by mothers who are still in school for further studies $59(26.6 \%)$. Family advice was the least factor with only $2(0.9 \%)$. The major factors influencing decisions for termination of breastfeeding includes WHO recommendations 75 (35.0\%) out of 222 multiple responses, closely followed by mothers who are still in school for further studies 44 (20.6\%. Family advice was the least factor with only 4 (1.9\%). Conclusion. The knowledge, attitude and intending practice on BF by the students were good, but more needs to be done in the area of knowledge because they are the future doctors who will play an important role in educating the society on breastfeeding.
\end{abstract}

Keywords: Knowledge, Attitude, Medical, Breastfeeding, Students, Jos

\section{Introduction}

Breastfeeding is a basic human activity, vital to infant and maternal health and of immense economic value to households and societies [1]. The WHO recommends that for the first six months of life, infants should be exclusively breastfed to achieve optimal growth, development, and health. Thereafter, infants should receive nutritionally adequate and safe complementary foods, while continuing to breastfeed for up to two years or more [2]. Breastfeeding remains the simplest, healthiest and least expensive feeding method that fulfills the infants' needs [3]. Exclusive breastfeeding (EBF) is defined as "an infant's consumption of human milk with no supplementation of any type (no 
water, no juice, no nonhuman milk, and no foods) except for vitamins, minerals, and medications until six months" [4].

It has been estimated that exclusive breastfeeding (EBF) reduces infant mortality rates by up to $13 \%$ in low-income countries [5]. Studies indicate that breastfed infants have fewer ear and respiratory tract infections, diarrheal illnesses, and atopic skin disorders [6-7]. Studies have also shown that the duration of breastfeeding was inversely associated with the risk of overweight. Children who had never been breastfed were $4.5 \%$ obese as compared with $2.8 \%$ in breastfed children [8].

The probability of death due to diarrhea and other infections is higher in infants who are either partially breastfed or not breastfed at all [4]. During the first two months of life, infants who are not breastfed are nearly six times more likely to die from infectious diseases than infants who are breastfed; between 2 and 3 months, non-breastfed infants are 4 times more likely to die compared to breastfed infants $[4,9]$.

The benefits of breast-feeding, to both mother and baby, have long been recognized [5-7, 10]. Despite strong evidences in support of EBF for the first six months of life, its prevalence has remained low worldwide [11-16]. In Nigeria, study done by Onche et al in Sokoto State, which is in Northern part of the country showed only 54 (31\%) of the mothers had adequate knowledge of exclusive breastfeeding with $94(53 \%)$ of them initiating breastfeeding immediately after birth. Only 55 (31\%) of the mothers practiced exclusive breastfeeding [17]. In the Western part of Nigeria, Dada et al [18] reported the initiation of BF within 1 hour of delivery to be $17 \%$ and Ogunlesi et al in Ileisha [19] reported a prevalence of $37.4 \%$. In Edo State, Nigeria, Salami et al reported that only $20 \%$ did exclusively for 6 months [20]. The difference in the knowledge score between these studies could be because they were conducted in different parts of the country, some in urban cities while somewhere in rural areas. The instruments and the questionnaires administered were also different.

There has not been much progress in the rate of EBF in Nigeria. The recent National Nutritional Health Survey done in 2018 documented a National prevalence of only $27 \%$. The National prevalence of initiation of BF in $1^{\text {st }}$ hour of life was $19 \%$ [21]. The results of EBF rate from other West African countries has also not been encouraging: Chad- $0.1 \%$, Burkina Faso- 50\%, Cameroon- 28\%, Ghana- 52\%, and Senegal- 33\% [22].

An important factor known to influence a mother's knowledge, attitude and practice of BF is the educational, counselling, teaching, emotional support and encouragement that mothers get from health care personnel's [23]. A Cochrane Review by Mcfadden reported that breastfeeding support from health professionals can be effective in extending the duration of breastfeeding [24]. It is therefore important, that health care personnel's acquire knowledge about breastfeeding during their period of study [25]. However, health professionals, do not always receive adequate breastfeeding education during their foundational education programme to effectively help mothers. Studies done on the knowledge, attitude and practice of medical and nursing students from different parts of the world showed that a lot more need to be done in educating and building the capacity of health professionals [26-30]. The knowledge of the students was mostly average and they were low for those in preclinical school. However, all the studies showed an improvement in the knowledge of the students after an educational intervention to build capacity of the students were done. Studies done by Szucs et and Utooba et al also identified gaps in the knowledge of practicing health care providers [31-32].

There has been a lack of fulfilling the WHO ten steps initiative for proper breastfeeding among female health care workers in tertiary care hospitals [33-34]. In Nigeria, studies have shown that there is poor knowledge among healthcare workers about Baby friendly Hospital Initiative awareness, that was programed that to help mothers' practice exclusive breastfeeding [35-37]. Though we expect health care professionals including doctors, nurses and various other health workers to be well informed regarding breastfeeding issues, studies have shown that it is not completely true. Assessing the knowledge of health professionals regarding breastfeeding have shown that there are some that are still unaware about benefits of breast feeding. Therefore, we need to adopt more organized measures to promote breast feeding.

Studies have shown that multiple factors like knowledge, attitude, beliefs, socio-cultural and physiological factors influence breastfeeding decision and practices [38-41]. A good predictor of the actual duration of breastfeeding is womens' pre-birth breastfeeding intention [42-44].

Breastfeeding is the greatest and best form of feeding for newborns; it is an important and cost-effective method of feeding for the healthy growth and development of infants and young children. Medical personnel have an essential role in promoting breast feeding as the ideal method of infant feeding and are effective in modifying maternal behavior positively towards breastfeeding. Medical students are also expected to have basic knowledge about breast feeding practices so that they can guide the community to promote breast feeding.

This study was designed to determine the knowledge, attitude and intention of Bingham University clinical and nursing students, Jos on Breastfeeding.

\section{Methods and Materials}

The study was a cross-sectional descriptive study. A selfdesigned semi-structured questionnaire was administered to the students who fulfilled the criteria and consented to the study. The sampling method was consecutive sampling of all the students until sample size was obtained. The proposal for the study was approved by the Ethical Committee of the Teaching Hospital. A total of 173 questionnaires were administered. The data was entered into SPSS statistical package version 20 and analyzed. Frequency tables and charts were drawn to show the awareness, knowledge, and 
perception of the students.

\section{Results}

The Knowledge on the definition of the term EBF was correct in $120(69.4 \%)$ of the students, $47(27.4 \%)$ of them got it wrong while 6 (3.45) did not known the definition of EBF.

Table 1. What is the definition of the term EBF?

\begin{tabular}{llll}
\hline Definition of EBF & Correct (\%) & Wrong (\%) & I don't know (\%) \\
\hline Yes & $120(69.4)$ & $47(27.2)$ & $6(3.4)$ \\
No & $53(31.6)$ & $126(72.8)$ & $167(96.6)$ \\
Total & $173(100.0)$ & $173(100.0)$ & $173(100.0)$ \\
\hline
\end{tabular}

EBF (exclusive breast feeding)
The knowledge on frequency of BF and the contents of breast milk was good with the least being $62 \%$, however the knowledge on whether fore milk is richer than hind milk was poor with only $82(47.4 \%)$ getting the correct answer. The early advantages of EBF was known by over $70 \%$ of the students and the contraindications to BF was gotten by over $60 \%$ of the students. The students' knowledge about some false notion on not giving EBM to sick babies, cause of nipple crack and inadequacy of BF for twin deliveries were good with over $70 \%$ of them knowing the right answers. The level of knowledge on the hormones responsible for BM production was poor with only $63(36.4 \%)$ getting the right answer and 97 (56.1\%) failing it while 13 (7.5\%) don't know (DK).

Table 2. Knowledge about Breastfeeding.

\begin{tabular}{|c|c|c|c|}
\hline Knowledge about Breastfeeding & Correct $(\%)$ & Wrong (\%) & DK $(\%)$ \\
\hline Frequency of BF should be $10-12 x$ a day & $108(62.4)$ & $40(23.1)$ & $25(14.5)$ \\
\hline Colostrum contains $>\mathrm{Ab} \&$ calories than mature milk & $142(82.1)$ & $12(6.9)$ & $19(11.0)$ \\
\hline About $88 \%$ of BM contains water & $123(71.1)$ & $14(8.1)$ & $36(20.8)$ \\
\hline Foremilk is richer than hindmilk & $82(47.4)$ & $52(32.1)$ & $39(22.5)$ \\
\hline Early initiation of EBF, prevents $\mathrm{PPH}$ & $133(76.9)$ & $12(6.9)$ & $28(16.2)$ \\
\hline EBF cannot help in child spacing & $129(74.6)$ & $31(17.9)$ & $13(7.5)$ \\
\hline EBF cannot be done by a mother with HIV & $125(72.3)$ & $39(22.5)$ & $9(5.2)$ \\
\hline EBM should be given to a sick baby who cannot suckle & $143(82.7)$ & $16(9.3)$ & $14(8.0)$ \\
\hline A major cause of nipple crack is poor attachment & $125(72.3)$ & $25(14.5)$ & $23(13.2)$ \\
\hline A mother with twins cannot feed them with only BM & $132(76.3)$ & $26(15.0)$ & $15(8.7)$ \\
\hline Prolactin \& Oestrogen are the hormones responsible for BM production & $63(36.4)$ & $97(56.1)$ & $13(7.5)$ \\
\hline Mood swing can affect BM production & $143(82.7)$ & $11(6.4)$ & $19(10.9)$ \\
\hline BF can prevent obesity later in life & $84(48.6)$ & $24(13.9)$ & $65(37.6)$ \\
\hline
\end{tabular}

DK (don’t know), BM (breast milk), PPH (post-partum haemorrhage)

The attitude of the students towards BF was very good with over $80 \%$ of them having good attitude towards BF, however 16 $(9.3 \%)$ will not BF for two years because they believe that it will make their breast to sag, while 23 (13.3\%) did not know if that is true and $62(77.5 \%)$ disagree with the statement.

Table 3. Attitude towards Breastfeeding.

\begin{tabular}{|c|c|c|c|}
\hline Attitudes & Agree (\%) & Disagree (\%) & DK $(\%)$ \\
\hline I will do/allow EBF for my baby & $163(94.2)$ & $4(2.3)$ & $6(3.5)$ \\
\hline I will breastfeed/allow breast feeding on demand & $154(89.0)$ & $16(9.3)$ & $3(1.7)$ \\
\hline I will not breastfeed/allow my wife to breastfeed in public & $15(8.7)$ & $132(76.3)$ & $26(15.0)$ \\
\hline I believe in abrupt weaning & $4(2.3)$ & $158(91.3)$ & $11(6.4)$ \\
\hline EBF is outdated and old fashioned & $1(0.6)$ & $168(97.1)$ & $4(2.3)$ \\
\hline I will introduce complementary feeds earlier than 6 months & $8(4.8)$ & $153(88.4)$ & $12(6.9)$ \\
\hline I will combine FM with BM for my baby in the $1^{\text {st }} 6$ months & $12(6.9)$ & $150(86.7)$ & $11(6.4)$ \\
\hline
\end{tabular}

The intending practice of BF was generally good among the students with over $90 \%$ agreeing to do initiate BF within 6 hours of delivery and practicing EBF for 6 months.

Table 4. Distribution of students based on intending practice of breastfeeding.

\begin{tabular}{lll}
\hline Intending practice & Freq. (173) & (\%) \\
\hline Initiation of breastfeeding after birth & & 169 \\
$0-6$ hours & 4 & 2.3 \\
$7-12$ hours & 0 & 0 \\
$13-18$ hours & 0 & 0 \\
$19-24$ hours & 0 & 2.7 \\
\hline
\end{tabular}




\begin{tabular}{|c|c|c|}
\hline Intending practice & Freq. (173) & $(\%)$ \\
\hline \multicolumn{3}{|c|}{ Type of pre-lacteal feeds I will give } \\
\hline Water & 30 & 17.3 \\
\hline Glucose water & 27 & 15.6 \\
\hline Holy water & 1 & 0.58 \\
\hline Nothing & 115 & 66.5 \\
\hline \multicolumn{3}{|c|}{ I will practice/advice EBF after birth } \\
\hline Yes & 167 & 96.5 \\
\hline No & 6 & 3.5 \\
\hline \multicolumn{3}{|c|}{ I will give only breast milk without water for a period of } \\
\hline 3 Months & 9 & 5.2 \\
\hline 4 months & 5 & 2.9 \\
\hline 5 months & 2 & 1.2 \\
\hline 6 months & 157 & 90.8 \\
\hline \multicolumn{3}{|c|}{ I will practice/advice the giving of EBM at work } \\
\hline Yes & 129 & 74.4 \\
\hline No & 21 & 12.1 \\
\hline I don’t know & 23 & 13.3 \\
\hline \multicolumn{3}{|c|}{ I will stop BF/advice my wife to stop between $12-18$ months } \\
\hline Yes & 72 & 41.6 \\
\hline No & 62 & 35.8 \\
\hline I don't know & 39 & 22.5 \\
\hline \multicolumn{3}{|c|}{ I will terminate breastfeeding at } \\
\hline 6 months & 18 & 10.4 \\
\hline 12 months & 37 & 21.4 \\
\hline 18 months & 116 & 67.1 \\
\hline 24 months & 2 & 1.2 \\
\hline
\end{tabular}

The major factors influencing decisions for EBF includes WHO recommendations $108(48.6 \%)$ out of 222 multiple responses, closely followed by mothers who are still in school for further studies $59(26.6 \%)$. Family advice was the least factor with only $2(0.9 \%)$

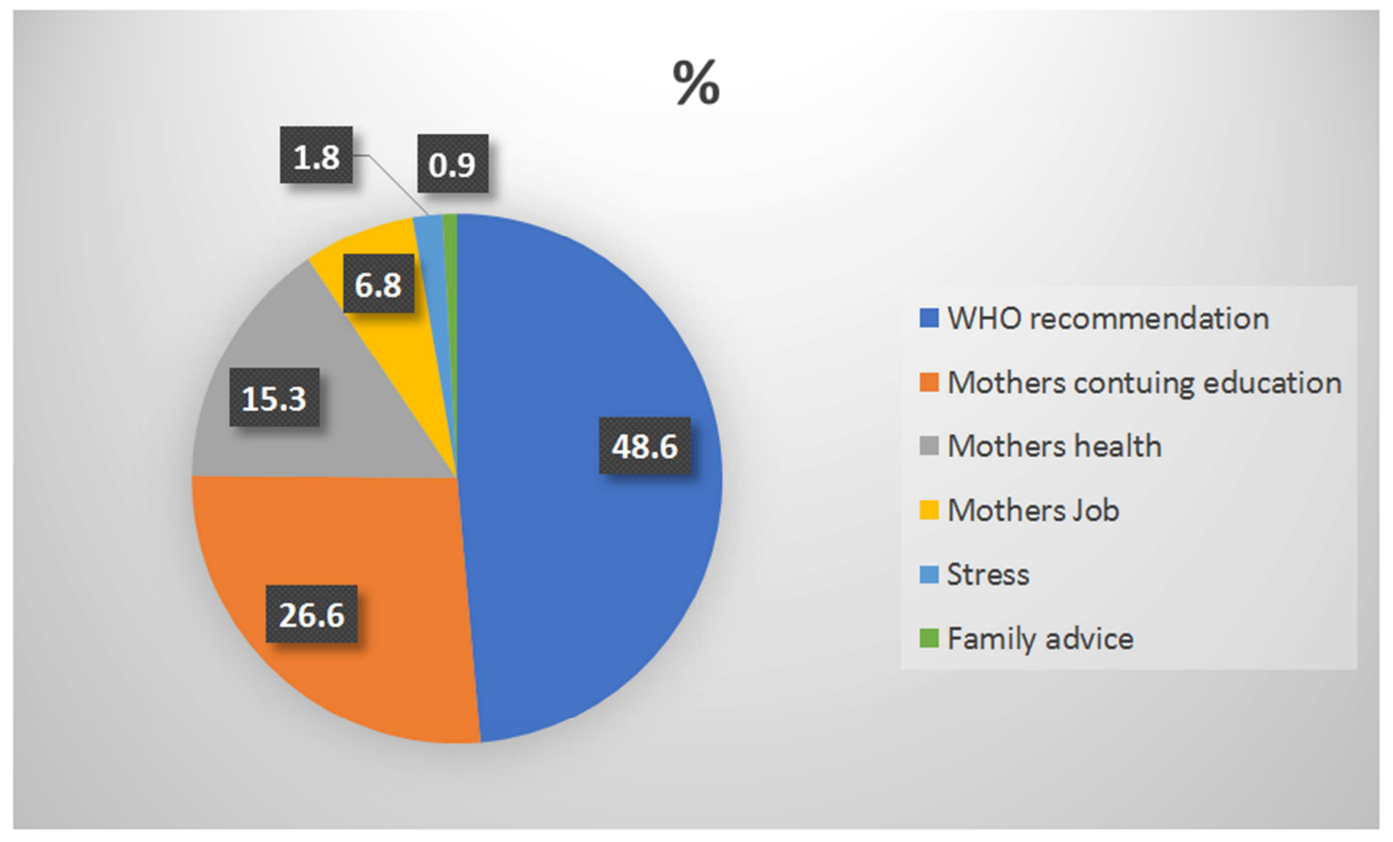

Figure 1. Factors influencing EBF.

The major factors influencing decisions for termination of breastfeeding includes WHO recommendations 75 (35.0\%) out of 222 multiple responses, closely followed by mothers who are still in school for further studies $44(20.6 \%$. Family advice was the least factor with only $4(1.9 \%)$ 


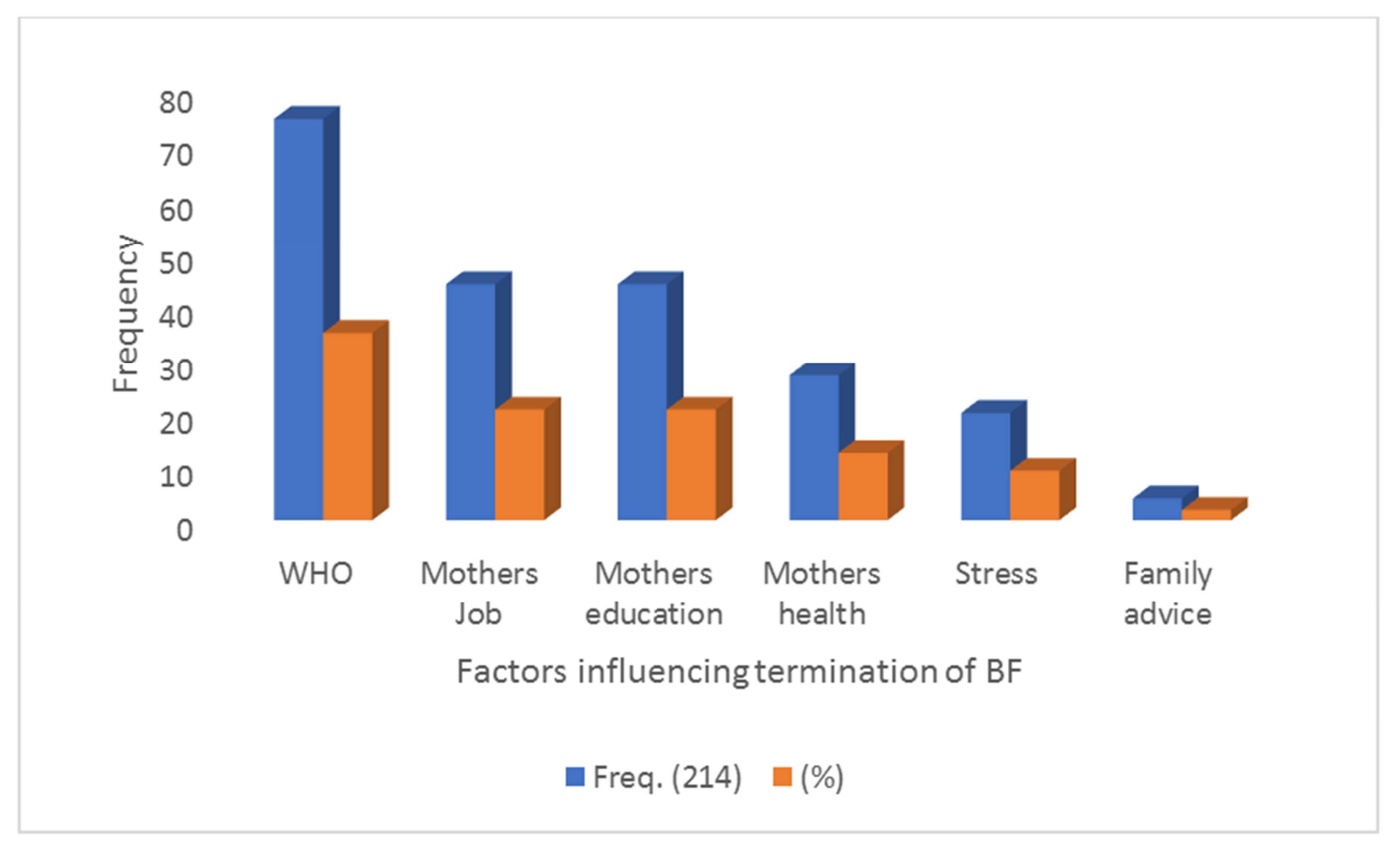

Figure 2. Factors influencing when to terminate breastfeeding decisions.

\section{Discussion}

The knowledge about the definition of EBM was fair with about $69 \%$ getting the correct answer. This is lower than expected because as clinical medical students, almost all the students are expected to know the definition of exclusive breastfeeding. However, the reason for the result could be because the curriculum of the 400L medical students did not include Paediatrics, where they are taught on breastfeeding. The result is comparable to what was obtained by studies done by Anjun et al [26], where $42 \%$ of the clinical medical students said EBF is for 4-6 months. The result is lower than that of Vidya et al [27], where the correct response for the definition of EBF was $84 \%$. The difference could be because of the medical students are from different levels, schools and countries. Another plausible explanation is because the instruments used to access and analyze the information are different. The knowledge of the frequency of breast feeding was fair with $62 \%$ getting the correct answer. This is comparable to the $75 \%$ that Anjun et al [26], obtained for similar question.

The general knowledge on the advantages of EBF and the contraindication to BF was above average, this is comparable to what Anjun et al [26], Amalina et al [45], and Vidya et al [27] got in their studies concerning knowledge on the advantages and the contraindication to breastfeeding. This is in contrast to what Devi et al [46] obtained in India, with only $22 \%$ of the medical students having knowledge above average, $54 \%$ scoring below average and $23 \%$ getting average. The difference in the results obtained with this study could be because of the scoring system used. The story is not too different for other affiliated health students [28]. This is also comparable to what seen in practicing health practitioners by Hillenbrand et al [47] where they found that the average knowledge of breastfeeding by the Paediatric and Medicine resident physicians was 69\%. Other studies on health care providers knowledge on breastfeeding by Utooba et al [32] and Szucs et al [31] also showed a gap in the knowledge on health care providers on breastfeeding.

The students' knowledge was poor in the aspects of knowing if fore milk is richer than hind milk, the hormones responsible for milk production and if breastfeeding can prevent obesity in the baby later in life. A plausible explanation for the poor result obtained could be because the lectures for the physiology of breastmilk production was given when they were in pre-clinicals.

The attitude of the students towards breastfeeding was good. This could be because they are medical students and would have been taught about the benefits of breastfeeding. The studies that were interventional, all showed an improvement in the knowledge and attitude of the students towards breastfeeding after educational sessions with videos, power points, lectures and counselling on breastfeeding. Wada et al [28] in their study also showed that the negative attitudes of the nursing students towards breastfeeding was because of lack of knowledge.

The intending practice of breastfeeding from the students was above average, although about $33 \%$ will give some form of prelacteal feeds to their babies. This could be explained by the fact that they already have a good attitude towards breastfeeding, therefore, their practice is expected to be good. The major factors influencing decisions for EBF includes WHO recommendations, closely followed by mothers who are still in school for further studies. Family advice was the least factor. This could be because they are medical students and they know about the WHO recommendation concerning breastfeeding. The result obtained in this study is in contrast to what Ogunba et al [48] obtained in her study where Job and health status are the major factors influencing breastfeeding decision. 


\section{Conclusion}

The general knowledge of the students concerning breastfeeding was above average, but it could be better because they are expected to know much more about breastfeeding than other health affiliated students. Their attitude and intending practice on BF were good. However, there is still room for improvement as few of them still intent to give pre-lacteal feeds. There are some gaps in their knowledge, attitude and intending practice of breastfeeding. Medical students being future doctors have a major role to play in helping mothers have adequate knowledge and positive attitude towards breastfeeding, therefore there is the need for the medical curriculum to lay emphasis regarding breastfeeding and include breastfeeding topics across levels of medical student.

\section{References}

[1] In fact Canada. Breastfeeding: a human right. Human and legal rights of breastfeeding women and children. 1997 [cited 2019 11th May]; Available from: https://www.infactcanada.ca/humright.

[2] WHO. Exclusive breastfeeding for six months best for babies everywhere. [cited 2018 11th May]; Available from: http://www.who.int.

[3] Kramer MS, Kakuma R. The optimal duration of Exclusive breastfeeding. A systematic review. WHO/NHO/01.08.2002: Geneva Switzerland.

[4] WHO. Indicators for assessing infant and young child feeding pratice part 3. 2010: Geneva.

[5] Jones G, Steketee R, Black R, Bhutta Z, Morris S. The Bellagio Child Survival Study Group. How many child deaths can we prevent this year?. Lancet 2003; 362: 65-71.

[6] Chantry C, Howard C, Auinger P. Full breastfeeding duration and associated decrease in respiratory tract infection in US children. Pediatr 2006;117: 425-32.

[7] Stuebe A. The Risks of Not Breastfeeding for Mothers and Infants. Rev Obstet Gynecol 2009; 2: 222-31.

[8] Harder T, Bergmann R, Kallischnigg G, Plagemann A. Duration of breastfeeding and risk of overweight: a metaanalysis Am J Epidemiol 2005; 162: 397-403.

[9] World Health Organization. Early Initiation of Breastfeeding: WHO. 2010: Geneva.

[10] Dennis CL. Breastfeeding initiation and duration: a 1990-2000 literature review. J Obstet Gynecol Neonatal Nurs 2002; 31: 12-32.

[11] Cai X, Wardlaw T, Brown DW. Global trends in exclusive breastfeeding. Int Breastfeed J 2012; 28: 1-12.

[12] Agampodi SB, Agampodi TC, Piyaseeli UK. Breastfeeding practices in a public health field practice area in Sri Lanka: a survival analysis. Int Breastfeed J 2007; 11: 1-13.

[13] Li R, Darling N, Maurice E, Barker L, Grummer-Strawn LM. Breastfeeding rates in the United States by characteristics of the child, mother or family: the 2002 National Immunization Survey. Pediatrics 2005; 115: 31-7.

[14] Vijayalakshmi P. Knowledge, attitudes, and breast feeding practices of postnatal mothers: A cross sectional survey. 2015; $9(4)$.

[15] Rajesh D, Bhavana D. A study on infant feeding practices in the urban slums : a cross sectional study. 2016; 3 (2): 350-4.

[16] Tadele N, Habta F, Akmel D, Deges E. Knowledge attitude and practice towards exclusive breastfeeding among lactating mothers in Mizan town, Southwestern Ethiopia: descriptive cross sectional study. Inter Breastfeeding J 2016; 11: 30-7

[17] Mo O, As U, Ahmed H. Knowledge and practice of exclusive breastfeeding in Kware, Nigeria. 2011; 11 (3).

[18] Dada OA, Akesode FA, Olanrewaju DM, Olowu OA, SuleOdu O, Fakoya TA et al. Infant feeding and lactational amenorrhea in Sagamu, Nigeria. African Journal of Reproductive Health 2002; 6 (2): 39-50.

[19] Ogunlesi TA, Dedeke OO, Okeniyi JA, Oyedeji GA. Infant and toddler feeding practices in the Baby Friendly Initiative (BFI) era in Ilesa, Nigeria. The Internet Journal of Nutrition and Wellness 2005; 1: 34-40.

[20] Salami LI. Factors influencing breastfeeding practices in Edo State, Nigeria. African Journal of Food and Agriculture, Nutrition and Development online 2006; 6: 50-59.

[21] National Nutritional Health Survey (NNHS) - Report - 2018.

[22] Infant and young child feeding-UNICEF DATA. [cited $5^{\text {th }}$ May 2019]. Available from: https://data.unicef.org/topic/nutrition/infant-and-young-childfeeding.

[23] Schmied V, Beake S, Sheehan A, McCourt C, Dykes F. Women's perceptions and experiences of breastfeeding support: a metasynthesis. Birth. 2011; 38 (1): 49-60.

[24] McFadden A, Gavine A, Renfrew MJ, Wade A, Buchanan P, Taylor JL, Veitch E, Rennie AM, Crowther SA, Neiman S, MacGillivray S. Support for healthy breastfeeding mothers with healthy term babies. Cochrane Database Syst Rev. 2017; 2: CD001141

[25] Lewin LO, O'Connor ME. Breastfeeding Basics: web-based education that meets current knowledge competencies. J Hum Lact. 2012; 28 (3): 407-13.

[26] Anjum Q, Ashfaq T, Siddiqui H. Knowledge regarding breastfeeding practices among medical students of Ziauddin University Karachi. J Pak Med Assoc 2007; 57: 480-3.

[27] Vidya G, Renuka M, Praveen K, Shirinivasa B. Impact of educational intervention on knowledge regarding infant feeding practices among medical students at Mysore. Inter J Health Allied Sci 2005;4: 230-33.

[28] Khriesat W, Ismaile S. Negative attitudes \& misinformation to breastfeeding among young generation in a nursing program. AMJ 2017;10 (11): 934-940.

[29] Satyavani A, Manikyamba D, Katreddi M. Knowledge of Medical and Nursing Students about Infant and Young Child Feeding (IYCF) Practices - A Hospital Based Study at Government General Hospital, Kakinada. Sch. J. App. Med. Sci. 2017; 5: 101-105. 
[30] Yang S, Salamonson Y, Burns E, Schmied V. Breastfeeding knowledge and attitudes of health professional students: a systematic review. International Breastfeeding Journal; 2018: $1-11$.

[31] Kinga A. Szucs, Donna J. Miracle, and Marc B. Rosenman. Breastfeeding Medicine. 2009. [cited $2019 \quad 10^{\text {th }}$ May]; Available from:http://doi.org/10.1089/bfm.2008.0108

[32] Utoo BT, Ochejele S, Obulu MA, Utoo PM, Utooba BF. Breastfeeding Knowledge and Attitudes amongst Health Workers in a Health Care Facility in South-South Nigeria: the Need for Middle Level Health Manpower Development. Clinics in Mother and Child Health 2012; 9: 1-5.

[33] Saima S. Knowledge Regarding Breast Feeding Practices among Nurses in Maternity Units of Health Care Facilities in Islamabad. Ann Pak Inst Med Sci 2012; 8: 249-51.

[34] World Health Organization. Protecting, Promoting and Supporting Breastfeeding: The Special Role of Maternity Services, a joint WHO/UNICEF statement.

[35] Okolo SN, Ogbonna C. Knowledge, attitude and practice of health workers in Keffi Local Government Hospitals regarding Baby-friendly Hospital Initiative (BFHI) practices. Eur J Clin Nutr 2002; 56: 438-41.

[36] Senbajo IO, Oshikoya KA, Ogbera OA, Wright KO, Anga AL. Breastfeeding policy and practices at the general paediatric outpatient clinic of a Teaching Hospital in Lagos, Nigeria. Int Breastfeed J 2014; 9: 1-8.

[37] Ogundeko T, Obisesan O, Ramyi M, Adu O, Akande T, Toma B. Impact-Evaluaation: Case study of Bassa LGA, Plateau State, Nigeria. J Den Med Sci 2014; 13: 21-25.

[38] Chambers JA, Mclnnes RJ, Hoddinott P, Alder EM. A systematic review of measures assessing mothers' knowledge, attitudes, confidence and satisfaction towards breastfeeding. Breastfeeding Review 2007; 15: 17-25.

[39] Chezem J, Friesen C, Boettcher J. Breastfeeding knowledge, breastfeeding confidence, and infant feeding plans: effects on actual feeding practices. J Obstetr Gynecol Neonatal Nursing 2003; 32: 40-7.

[40] Kong SKF, Lee DTE. Factors influencing decision to breast feed. J Adv Nursing 2004; 46: 369-79.

[41] Papinczak TA, Turner CT. An analysis of personal and social factors influencing initiation and duration of breastfeeding in a large Queensland maternity hospital. Breastfeeding Review 2000; 8: 25-33.

[42] Forster DA, McLachlan HL, Lumley J. Factors associated with breastfeeding at six months postpartum in a group of Australian women. Int Breastfeeding J 2006; 18: 1-18.

[43] Jiang H, Li M, Yang D, Wen LM, Hunter C, Qian X, et al. Awareness, Intention, and Needs Regarding Breastfeeding: Findings from First-Time Mothers in Shanghai, China. Breast feed Med 2012; 7: 526-34.

[44] Donath S, Amir LH. Relationship between prenatal infant feeding intention and initiation and duration of breastfeeding: a cohort study. Acta Paediatrica 2003; 92: 352-6.

[45] Amalina E, Lattif AL, Nor Afiah MZ, ShukorA M N, Yew K $\mathrm{M}$. Knowledge and attitude towards breastfeeding among medical students in a public university in Malaysia. Int Med J 2004; 3: 67-73.

[46] Devi HS, Avinash K, Vijaya E, Sourab P, Singh TA. Knowledge of breastfeeding among medical students in Manipur, India. 2013. [cited 201912 May]; Available from: http://www.ijhas.in, IP: 197.210.54.

[47] Hillenbrand KM, Larsen PG. Effect of an educational intervention about breastfeeding on the knowledge, confidence, and behaviors of pediatric resident physicians. Pediatrics 2002; 110: 59-64.

[48] Ogunba BO, Agwo EO. Knowledge attitude and intending practice of female undergraduates about breastfeeding. AJFAND 2014; 4: 9039-54. 